\title{
AVALIAÇÃO DO DESENVOLVIMENTO DA PREENSÃO MANUAL EM CRIANÇAS DE 4 A 12 MESES
}

\author{
EVALUATION OF MANUAL PREHENSION DEVELOPMENT \\ IN CHILDREN BETWEEN FOUR AND TWELVE MONTHS
}

Micheli H. Nakaura ${ }^{1}$

Paulo A. Riheiro ${ }^{2}$

Mônica R. S. Porto ${ }^{3}$

NAKAURA, M.H.; RIBEIRO, RA.; PORTO, M.R.S. Avaliação do desenvolvimento da preensão manual em crianças de 4 a 12 meses. Rev. Bras. Cresc. Desenu Hum., São Paulo, 14(1), 35-42, 2004.

\begin{abstract}
Resumo: Este trabalho teve como objetivo avaliar o desenvolvimento da preensão manual em crianças de 4 a 12 meses de idade institucionalizadas, em berçarios privados e em berçarios municipais, para verificar se existe um atraso no desenvolvimento da preensão e quais os possíveis fatores que podem interferir nesse desenvolvimento. Não foi encontrada na literatura uma avaliação do desenvolvimento da preensão manual em relação aos itens a serem avaliados neste trabalho; desse modo, optou-se por basear tal avaliação na revisão literária relacionando o desenvolvimento da preensão e a faixa etária da criança. Foram avaliadas 68 crianças de 4 a 12 meses de idade, de ambos os sexos, divididas em três grupos. Os resultados mostraram que as crianças institucionalizadas apresentaram um atraso no desenvolvimento da preensão manual na maioria dos itens avaliados. Observando o ambiente e a rotina dessas crianças, pôde-se perceber uma privação de espaço fisico, de brinquedos e de estímulos táteis e senso-perceptivos, o que pode estar interferindo na aquisição de novos padrões de preensão e de manuseio dos objetos. Apontase para a importância do fisioterapeuta, entre outros profissionais da área da saúde, em relação ao desenvolvimento infantil e, em especial, à preensão manual.
\end{abstract}

Palavras chave: desenvolvimento infantil; preensão manual.

\section{INTRODUÇÃO}

Durante o crescimento e a maturação de uma criança, ocorrem grandes alterações no desenvolvimento motor normal, bem como no anormal. Os movimentos iniciais, e bastante simples dos recém-nascidos, alteram-se e tornamse mais variados e complexos. Estágio por estágio, as primeiras aquisições são modificadas, elaboradas e adaptadas para padrões e habilidades mais finos e seletivos (BOBA^$\wedge \mathrm{TH}, 1989)$.
O conhecimento do desenvolvimento motor, segundo $\mathrm{SHE}^{\wedge} \mathrm{PHE} \wedge \mathrm{RD}$ ( 1996), é de fimdarnental importância na clínica pediátrica, principalmente em situações na quais o lactente pode apresentar ou correr o risco de desenvolver algum tipo de distúrbio motor.

Sabe-se que o DNMP (desenvolvimento neuro-psicomotor) da criança depende de vários fatores, dentre eles, os fatores genéticos, as condições sócio-econômicas e culturais, as influências do ambiente, as experiências e eventos pas-

1 Trabalho desenvolvido pela Diretoria Acadêmica da Área de Ciências da Saúde - Curso de Fisioterapia - UNIBAN-MC Graduada em fisioterapia em 2003 pela UNIBAN-MC; especializando em Fisioterapia Pneumofuncional da irmandade da Santa Casa de Misericórdia de São Paulo - R. São Joaquim, 309 apt. 61 bloco 2 - CEP: 01508-001 - São Paulo-SP. E-mail: xaverinha_hi@hotmail.com

2 Diretor clinico da Cenin-Clinica e Cirurgia Pediátrica; docente da UNIBAN; mestre em Biociência Aplicada UNIBAN; médico da Secretaria de Saúde de São Paulo. Endereço: Av. Ataliba Leonel, 93 Conj. 35 Santana - CEP: 06311-080 - São Paulo-SP.

3 Diretora clínica do NDTI - Núcieo de Desenvolvimento Terapêutico integrado; mestre em Distúrbios do Desenvolvhnento/ Mackenzie; doutpranda da FMUSP. Endereço Av. Agami, 120 - Moema - CEP 04522-000 - São Paulo. 
sados, entre outros (SHEPHERD, 1996; BURNS \& MAC DONALD, 1999).

Helen BEE (1996) complementa que o desenvolvimento é um produto de várias formas de interação entre influências internas e externas. Para HAMMASTROM e col. (1992), é importante a vivência infantil por meio de sensações, percepções, capacidades e habilidades corporais, globais e específicas, que serão desenvolvidas a partir das recepções de estímulos sensório-motores do meio externo para o interno, sedimentando, assim, essas experiências.

Com isso, pode-se perceber a importância de um ambiente favorável para que a criança se desenvolva, inclusive em relação à capacidade de explorar o ambiente usando a mão, que é uma parte do corpo pela qual ela pode executar suas tarefas do dia-a-dia, podendo, por meio delas, sentir, gesticular e satisfazer seus desejos. "É importante analisar o desenvolvimento da preensão manual para que se saiba interferir quando for necessário, ou ainda para uma estimulação correta” (HAMMASTROM et al, 1992, p. 26).

Este trabalho pretende realizar uma revisão da literatura sobre os fatores que podem interferir no desenvolvimento infantil. Pretende, igualmente, comparar três grupos de crianças, de 4 a 12 meses de idade, que permanecem em instituições e em berçários privados e municipais, utilizando uma avaliação do desenvolvimento da preensão manual dessas crianças. Esta comparação entre três grupos de crianças com diferentes experiências interativas e ambientais tem o objetivo de averiguar se ocorreria ou não uma diferença no desenvolvimento da preensão manual e quais seriam os possíveis fatores que podem interferir nesse desenvolvimento.

Pretende, desta maneira, responder às seguintes questões: Existe um atraso no desenvolvimento da preensão manual nessas crianças? Quais são os fatores que podem estar interferindo no desenvolvimento de sua preensão manual?

\section{O DESENVOLVIMENTO DA PREENSÃO MANUAL}

"Desde os tempos primitivos, a mão tem se desenvolvido para expressar o comportamento biopsicossocial do ser humano". É importante ressaltar as funções básicas das mãos, como o empurrar ou bater em objetos, e não apenas a locomoção e a preensão (HAMMASTRON et al, 1992, p. 29).

Para MEYERHOF (1994), a preensão depende de vários fatores, como a percepção visual, a capacidade motora global da criança e a coordenação óculo-manual.
Durante o primeiro ano de vida, a mão evidencia uma acelerada sucessão de progressos, de integração de funções e de aquisição de múltiplas conquistas que, ao se exercitarem, enriquecemse reciprocamente e firmam as bases para novas habilidades. Neste desenvolvimento, salienta-se claramente a característica da maturação neuropsíquica: o progresso no sentido do proximal para distal, a evolução do reflexo ao cortical, e do inconsciente ao voluntário, por meio da exercitação e da supuração desses reflexos e da organização da conduta (CORIAT, 1991).

Podemos definir o reflexo de preensão palmar como sendo "qualquer estímulo proprioceptivo ou tátil na palma da mão ou na face palmar dos dedos que provoca o fechamento da mão" (KOUPERNIK apud MEYERHOF, 1994, p. 26).

À medida que o Sistema Nervoso Central se desenvolve, e com a integração do controte da posição dos olhos, da cabeça e da correta coordenação do sistema motor ocular, a criança vai desenvolvendo a capacidade de fixação, de coordenação manual e de aprendizagem (BRANDÃO, 1984).

Segundo CORIAT (1991), com o reflexo óculo-manual que se atenua no decorrer do $3^{\circ}$ mês para desaparecer no $4^{\circ}$ mês, fica estabelecida a coordenação sensório-motora entre as mãos, os olhos e a boca, propiciando à criança obter um melhor conhecimento das superficies dos objetos, sua consistência, textura etc. por meio do talo oral, que enriquece e complementa os dados recebidos pela visão, e do talo manual.

Segundo MEYERHOF (1994), podemos considerar quatro estágios de desenvolvimento dos padrões adquiridos de preensão, lembrando que a aquisição de um tipo de preensão não implica no desaparecimento do anterior e que esse será utilizado nos estágios subseqüentes.

$\Rightarrow$ Primeiro periodo - "preensão cúbitopalmar” (4 meses): realizada pelos 3 últimos dedos apertando o objeto apreendido contra a eminência hipotênar, sendo que o polegar permanece praticamente inativo, o punho se fiexiona e a mão se desvia para o lado cubital (MEYERHOF, 1994).

Neste período, os dois membros dirigemse simetricamente para o objeto e a criança deixa rapidamente cair o que segura. É uma preensão fraca e de curta duração (BRANDÃO, 1984; GESELL, 1992; MEYERHOF, 1994).

$\Rightarrow$ Segundo período - "preensão palmar simples ou de aperto" (5-6 meses): neste período, o objeto é apreendido entre os 4 dedos longos e a palma com adução do polegar. A flexão dos dedos não é acompanhada obrigatoriamente da flexão do punho (MEYERHOF, 1994). A aproximação do objeto é realizada pelos movimentos 
da escápula, dos ombros e dos cotovelos e é preferencialmente bimanual e simétrica (BRANDÃO, 1984; KNOBLOCH \& PASSAMANICK. 1987).

Para SHEPHERD (1996), a criança de 6 meses não consegue manter um objeto em uma das mãos e segurar o outro com a outra mão.

Em torno dos 6 meses, atenua-se a tendência bimanual para agarrar objetos; porém, cada vez que uma das mãos apanha algo, transfere-se para a outra que, por sua vez, devolve à primeira e assim sucessivamente (CORIAT, 1991; BURNS \& MAC, DONALD. 1999).

$\Rightarrow$ Terceiro período - "preensão rádiopalmar” (7-8 meses): o polegar entra em ação pela primeira vez, ele é aduzido em direção ao indicador. Aparece o que GESELL (1992) chama de preensão fina ou pinça inferior ou em chave. Não é uma pinça verdadeira, pois o indicador e o polegar ficam estendidos num mesmo plano (MEYERHOF, 1994; EHARDT, 1997).

Durante o período de 7 meses, a criança está descobrindo o tamanho, a forma, o peso e a textura das coisas. Coloca os objetos na boca, tirao, olha para o brinquedo, bate a mão na mesa e é capaz de segurar dois objetos ao mesmo tempo.

$\Rightarrow$ Quarto período - "preensão rádio-digital ou em pinça superior" (9-12 meses): GESELL (1928, in SHEPERD, 1996) descreve que "em torno dos 9 meses, o lactente costuma ter desenvolvida uma preensão em pinça um tanto imatura; na idade de 12 meses, ele já é capaz de segurar objetos entre as pontas dos dedos polegar e o indicador.

LÊ (1992) complementa que, no $9^{\circ}$ ou no $10^{\circ}$ mês, a criança explora os buracos e rachaduras e distingue superfícies diferentes, assim como tem a noção de relevo e profundidade. Aos 10 meses, a curiosidade do seu indicador leva-o a cada vez mais longe na terceira dimensão. Os seus manuseamentos são mais discriminados e, por vezes, são mesmo graciosos (GESELL, 1992).

A individualidade da pinça vai adquirindo mais precisão. No início, a sinergia entre os extensores e os flexores é imperfeita, e a criança ainda não tem uma representação exata do tamanho do objeto a ser pego, abrindo exageradamente a mão antes de alcançá-lo (MEYERHOF, 1994).

Entre os 9 e os 12 meses de idade, as mãos começam a ser usadas para apalpar e sentir superfícies de texturas diferentes, para achar e pegar coisas pequeninas, para levar alimento à boca e expressar e comunicar as necessidades, além de servirem nos relacionamentos sociais, sob forma de acenos e bate palmas (BURNS \& MAC DONALD, 1999).
Dessa forma, os dados que as mãos como órgãos táteis e preensores of erecem, acompanhados e enriquecidos pelos que chegam dos olhos e ouvidos, colaboram para a formação de novas estruturas, e a criança adquire noções de tempo e espaço, imprescindíveis para conhecer o mundo que a rodela e para diferenciar-se dele. Juntamente com o aprendizado motor manual, leva-se em conta o conjunto de experiências vitais para proporcionar à criança uma maturidade psicomotora normal (CORIAT, 1991).

\section{MATERIAIS E MÉTODO}

Foram elaborados dois questionários: um para as crianças institucionalizadas e outro para as crianças dos berçários, sendo que a elaboração foi feita com o objetivo de: selecionar as crianças a serem avaliadas; obter um maior controle dos grupos estudados, e, principalmente, obter a autorização dos responsáveis para a participação das crianças nos estudos, sendo o objetivo do estudo comparar as crianças (está faltando completar a frase)

Foram escolhidas crianças de 4 a 12 meses de idade, de ambos os sexos, nos 3 grupos avaliados: de berçários privados (A), de berçários municipais (B) e de crianças institucionalizadas (C).

Foram excluídas as crianças nascidas prétermo, pois, segundo DRILLINE e cols (1998, in BURNS \& MAC DONALD, 1999), foram descritas algumas diferenças no desempenho motor na população de crianças nascidas prétermo e/ou que permaneceram por muito tempo sob tratamento neonatal intenso; crianças que fazem uso de órtese para visão; portadoras de má formação congênita ou com distúrbio neurológico.

As avaliações foram realizadas durante 0 período de novembro de 2002 a maio de 2003, nas próprias instituições e berçarios, onde a criança, quando possível, permanecia em uma sala somente com o examinador. Em outros casos, as avaliações foram realizadas em um local onde a criança não pudesse perder a atenção e se distrair. Cada criança foi avaliada no mínimo duas vezes em dias diferentes e nas mesmas condições da avaliação anteriormente realizada, enquanto estava com a mesma idade, para que obtivéssemos resultados mais efetivos, levando-se em conta que a criança poderia apresentar diferenças de desempenho.

Em situações na qual a criança apresentava uma diferença significativa no seu desempenho ou na qual algum item da avaliação não podia ser esclarecido, uma terceira ou quarta avaliação era realizada. 
Os materiais utilizados para as avaliações foram baseados na literatura (HOLHSTEI^^N, 1982; MEYERHOF, 1994), relacionados aos quatro tipos de preensão avaliados. Foram utilizados chocalhos, cubos de madeira (2,5 cm e $3 \mathrm{~cm})$, argolas de plásticos (6,5 cm de diâmetro), caixas de papel (13 cm x 3,5 cm), caixas de plástico (6 cm x 1,5 cm) e bolas pequenas para todas as crianças.

Durante a avaliação, foram observados: o tipo de preensão realizada; o reflexo de preensão palmar; o controle de tronco; a coordenação dos membros superiores; a coordenação óculo-manual; a exploração do objeto (levar o objeto à boca, passar de uma mão a outra; bater um contra o outro, segurar mais de um objeto ao mesmo tempo); as sincinesias; a preensão bimanual; a exploração do indicador e a preferência em realizar a preensão.

Por meio da revisão da literatura, não foi encontrada uma avaliação do desenvolvimento da preensão manual que incluísse os itens avaliados neste trabalho. Com isso, optou-se em basear a avaliação na revisão literária, relacionando o desenvolvimento da preensão manual e a faixa etária da criança.

Para realizar a revisão bibliográfica, foram pesquisados livros e artigos nas bibliotecas da UNIBAN (MC), FMUSP e da BIREME. Os artigos procurados foram dos anos de 1982 a 2002, sendo as palavras chaves utilizadas desenvolvimento infantil e preensão nos idiomas português, inglês e espanhol. Não houve restrição para a busca de livros em relação ao ano de publicação devido à ausência de novas edições.

\section{Procedimento}

Primeiramente, era avaliado o estado geral da criança para que, em condições nas quais ela se apresentasse com sono, com febre, dispersa ou chorosa, a avaliação não fosse realizada.

A criança permanecia sentada com ou sem apoio, dependendo do seu controle de tronco, de maneira que conseguisse ter os movimentos livres dos membros superiores. Eram oferecidos os objetos, como os chocalhos, para que ela se acostumasse com a situação e com o avaliador. Somente após ela ter se mostrado confortável e alerta, a avaliação era iniciada, com uma duração média de 10 minutos por criança.

Os objetos foram oferecidos um a um dentro do campo visual da criança, na altura no queixo e a uma distância (em torno de $15 \mathrm{~cm}$ ) na qual o alcance fosse possível (SIDDIQUI, 1995). A ordem dos objetos foi baseada em grau de dificuldade, começando com chocalho, depois argolas, caixinhas de papel, caixinhas de plástico, cubos de madeira e, finalmente, a bolinha.
Após a apresentação do objeto à criança, se ela não mostrasse interesse, o avaliador tentava chamar a atenção da criança por meio do som emitido pelos objetos durante mais ou menos 15 segundos. Se a criança continuasse desinteressada, a avaliação era realizada em um outro momento.

Em seguida, a tentativa da preensão ou a preensão em si realizada pela criança era observada, levando-se em consideração os aspectos citados anteriormente. A criança permanecia com o objeto durante o tempo que fosse necessário para serem observados todos os itens em avaliação, ou até a criança soltar ou perder o interesse pelo objeto, sendo, assim, oferecido à criança o próximo objeto nas mesmas condições.

Em situações na qual a criança recusava soltar o objeto, tentava-se distraí-la ou chamar a atenção com o próximo objeto a ser avaliado. Caso não fosse possível, o objeto era tirado da sua mão e oferecia-se o objeto seguinte.

\section{RESULTADOS}

Foram avaliadas 68 crianças, sendo 33 (48.5\%) do sexo feminino e 35 (51.5\%) do sexo masculino durante o período de Novembro de 2002 a maio de 2003, tendo sido realizadas 150 avaliações, em uma média de 2.20 avaliações para cada criança. A idade média das crianças foi de 8.27 meses para o sexo feminino e 7.6 meses para o sexo masculino.

Dezessete crianças não participaram do estudo: 3 (17.6\%) nasceram pré-termo; 7 (41.1\%) não foram autorizados pelos pais; 4 (23.7\%) ficaram doentes durante o período das avaliações; e 3 (17.6\%) não se adaptaram ao examinador.

De acordo com o gráfico 1, pode-se observar que as crianças dos berçários municipais entre 4 a 6 meses de idade foram as que apresentaram uma maior porcentagem de atraso do tipo de preensão manual para a idade.

O gráfico 2 mostra que, nos três grupos estudados, nenhuma criança acima de 7 meses de idade apresentou o reflexo de preensão manual, sendo que $17 \%$ das crianças entre 4 a 6 meses de idade do grupo B ainda apresentavam algum esboço do reflexo de preensão palmar, o que correspondeu a 3\% e 13\% nos grupos A e C, respectivamente.

Pode-se observar, no gráfico 3, que 43\% das crianças institucionalizadas entre 7 a 9 meses não apresentaram um bom controle de tronco para a sua idade. $43 \%$ das crianças do grupo $B$ dentro da mesma faixa etária apresentaram um controle de tronco necessário para manter a pos- 


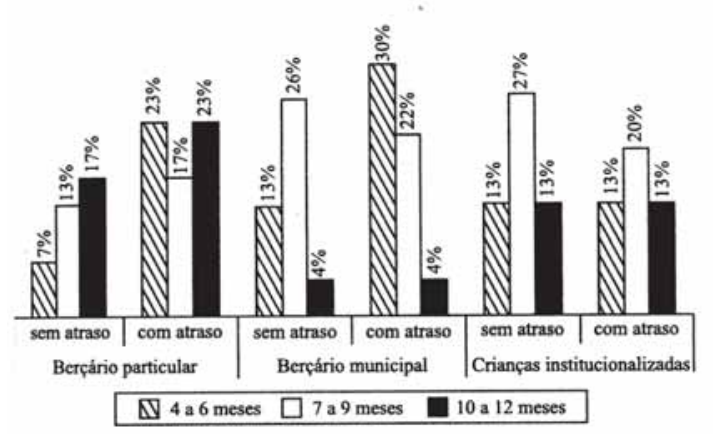

Gráfico 1. Tipo de preensão.

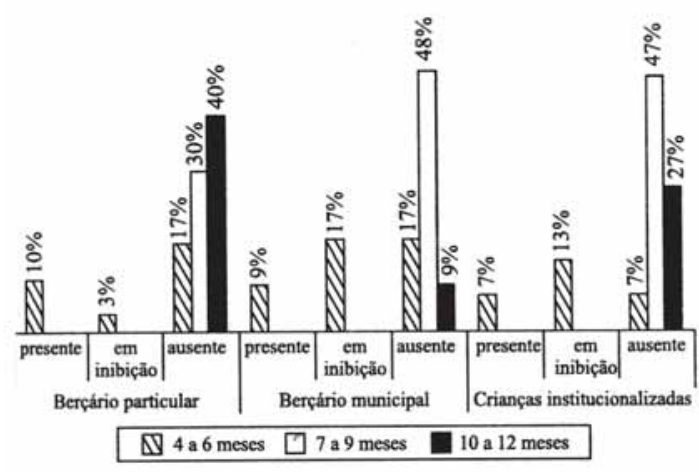

Gráfico 2. Reflexo de preensão palmar.

tura sentada sem apoio com a movimentação dos membros.

Pode-se observar que $43 \%$ das crianças institucionalizadas entre 7 e 9 meses não apresentaram um bom controle de tronco para a idade. $43 \%$ das crianças do grupo B, dentro da mesma faixa etária, apresentaram um controle de tronco necessário para manter a postura sentada sem apoio com a movimentação dos me^inbros superiores. (Gráfico 3 ).
O gráfico 4 ilustra o desempenho em relação à coordenação dos membros superiores ao realizar o alcance e a preensão. Pode-se observar que as crianças dos berçários particulares e privados mostraram desempenhos semelhantes. Dentro do grupo C, 20\% das crianças entre 7 a 9 meses não apresentaram um controle adequado para a idade.

Nos 3 grupos estudados as crianças mostraram um bom desempenho quanto à coordenação óculo-manual (Gráfico 5) sendo que das crianças do grupo B, entre 7 a 9 meses, $48 \%$ obtiveram um bom resultado.

O gráfico 6 mostra que 53\% das crianças institucionalizadas apresentaram um déficit na exploração do objeto, sendo que as criança do grupo B foram as que apresentaram o melhor desempenho, observando uma boa exploração do objeto em $73 \%$ delas.

$60 \%$ das crianças entre 10-12 meses dentro do grupo C não apresentaram uma boa exploração do dedo indicador, em comparação com o grupo A onde $44 \%$ não a apresentaram (Gráfico 7).

Foi observado que a maioria das crianças, 66 (97\%) apresentaram uma preferência em realizar a preensão com o lado direito.

A sincinesia em relação à preensão bimanual tòi observada nas 68 (100\%) crianças.

\section{DISCUSSÃO}

Para EHARDT (1997), o estudo da preensão concentra-se na observação das $\wedge^{\prime}{ }^{\prime}$ 'a ses dos padrões de maturação em crianças nor $\sim$ nais, e as crianças com deficiência no desen volvimento necessitam de programas de inter venção estruturados de modo a prevenir os desvios e estimular a sua aprendizagem. Com os resultados obtidas neste trabalho, pode-

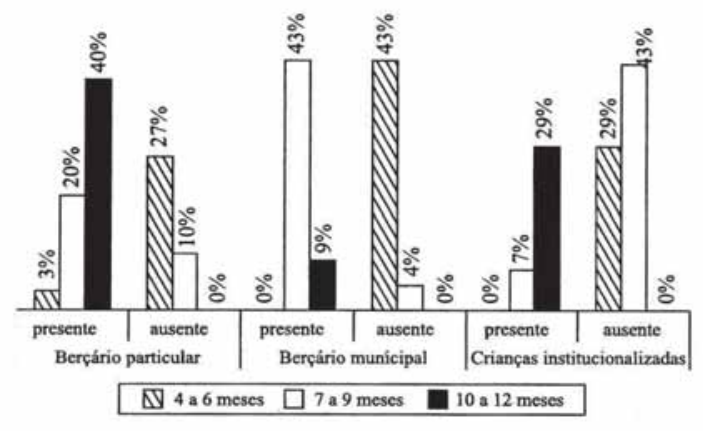

Gráfico 3. Controle de Tronco.

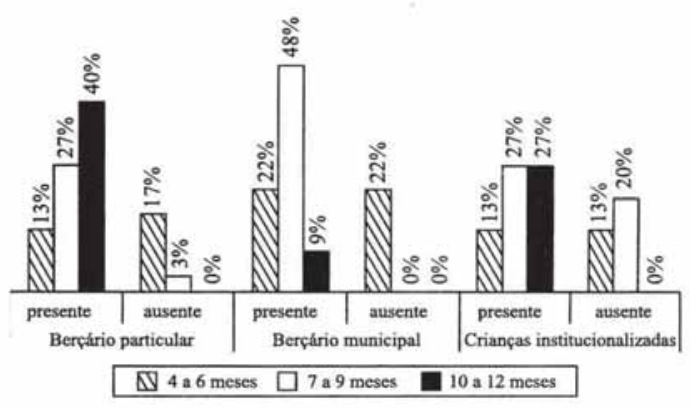

Gráfico 3. Coordenação membros superiores. 


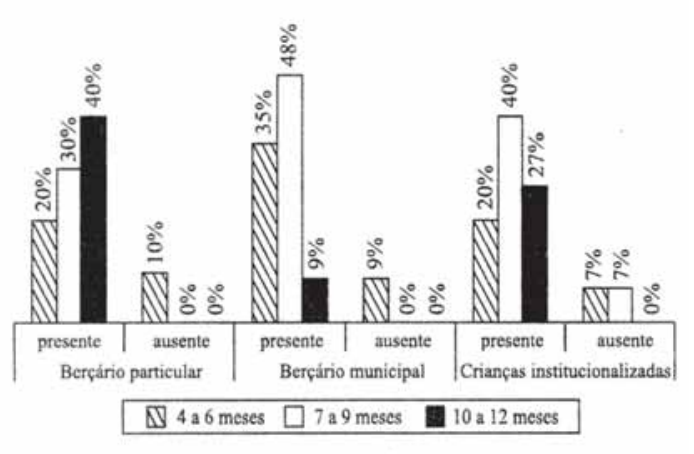

Gráfico 5. Coordenação Oculo-manual.

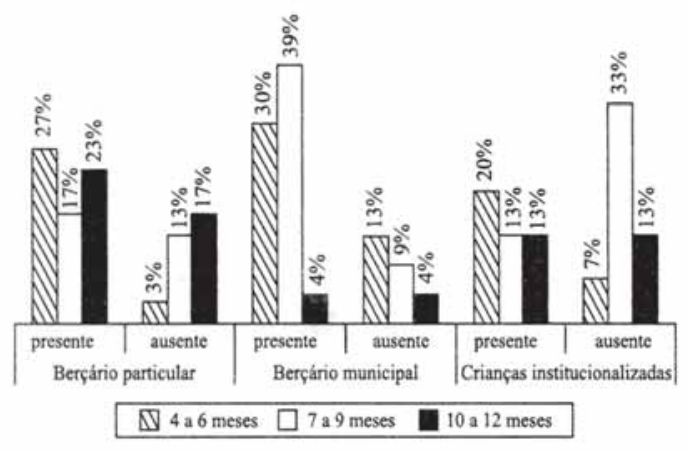

Gráfico 6. Exploração do objeto.

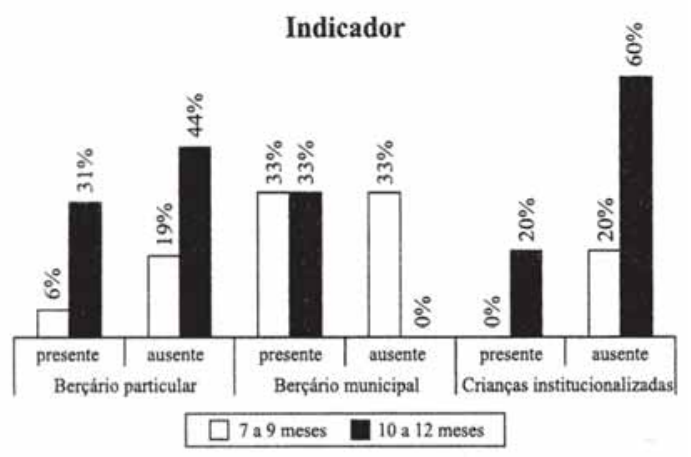

Gráfico 7. Indicador.

se perceber que $44(64,7 \%)$ das crianças avaliadas apresentaram um atraso em relação ao tipo de preensão, sendo as crianças entre 4 a 6 meses do grupo $\mathrm{B}$ foram as que apresentaram os piores desempenhos (30\%). Tais resultados podem ser comparados com um estudo longitudinal realizado em 30 crianças, de 0 a 12, meses por SANTOS e col. (2001) que mostrou que as crianças brasileiras tinham um atraso no desenvolvimento da preensão manual se comparado com as crianças americanas, sendo uma possível explicação para essa diferença uma variação na experiência e na influência da maturação biológica no comportamento dessas crianças.

Helen BEE (1996) concorda com a explicação de BURNS e MAC DONALD (1999) de que cada criança apresenta um padrão característico de desenvolvimento, visto que suas características inerentes sofrem a influência de uma cadeia de transações que se passam entre a criança e seu ambiente. Esses autores relatam ainda a existência de uma variabilidade individual considerável entre as crianças dentro de um mesmo grupo e da mesma faixa etária.

Por outro lado, CONOLLY e ELLIOT (1972, in SIDDIQUI, 1995) descrevem que a configuração de novos padrões de preensão está baseada na habilidade de ação relacionada com a capacidade cognitiva da criança; porém, esses autores não explicam como a criança pode utilizar o desenvolvimento cognitivo e como ele surge.

Uma explicação mais completa parece ser o que SHEPHERD (1996), CASE-SMITH e cols, (1998) e FLEHMING (2002) oferecem. Esses autores defendem a idéia de que os padrões de movimentos parecem ser o resultado da interação entre o ambiente como um processo de experiências sensoriais e do desenvolvimento neurológico das habilidades da criança.

Observa-se que as crianças entre 4 a 6 meses dos berçários privados e municipais que ainda apresentavam o reflexo de preensão manual mostraram atraso no tipo de preensão a ser realizado, o que leva a supor que a permanência do reflexo pode influir negativamente na aquisição de novos padrões de preensão.

Os resultados obtidos estão também de acordo com BRANDÃO (1984) e MEYERHOF (1994), pois a criança apresenta uma diminuição da atividade reflexa a partir do $3^{\circ}$ mes, ocorrendo no $4^{\circ}$ mes de idade o início da preensão voluntária, e aos 5 ou 6 meses, a preensão túnica dos flexores. Nenhuma das crianças a partir de 7 meses apresentou o reflexo de preensão palmar. Entretanto, crianças até 6 meses de idade dentro dos três grupos ainda apresentavam esse reflexo, sendo mais evidente nas crianças do grupo B.

No grupo $C$, as crianças entre 7-9 meses não apresentaram um bom controle de tronco para a sua faixa etária, $20 \%$ delas não tiveram uma boa coordenação dos membros superiores para realizar o alcance até o objeto.

No caso dessas crianças, observou-se uma privação em relação à troca de posturas. Essas crianças permaneciam a maior parte do tempo nos berços, em decúbito dorsal ou ventral, e poucas vezes 
eram tiradas dessa posição e colocadas em outras posturas, principalmente na postura sentada.

Segundo um estudo realizado por WILSON e TROMBLY, em 1984, descrito por CASESMITH e col. (1989), o desenvolvimento proximal não é necessário como um pré-requisito para o desenvolvimento motor distal. Entretanto, esse estudo utilizou uma amostra pequena. Os autores relataram também que a relação entre o controle proximal e distal não é necessariamente direta.

Por outro lado, para CORIAT (1991), SIDDIQUI (1995) e BUENO (1998), o desenvolvimento ocorre da musculatura proximal para a distal.

Complementando essa linha de pensamento, ILLINGWOTH, (1975) e GRANDY e MOORE, (1981) (in CASE-SMITH et al., 1989) relatam que o desenvolvimento da preensão tem sido observado como um progresso proximal para distal, do palmar para a região das polpas digitais, e as crianças finalmente desenvolvem um padrão de preensão que geralmente progride de uma preensão mais grosseira ou palmar para uma preensão mais delicada, em pinça.

Observou-se que as crianças com uma boa coordenação dos membros superiores apresentaram uma coordenação óculo-manual satisfatória.

Esse resultado mostra-se de acordo com as observações de BRANDÃO (1984), HAMMASTRON e col. ( 1992) e SHEPHERD (1996), indicando uma relação entre a coordenação dos movimentos dos membros superiores e a coordenação óculo-manual, sendo que é preciso um sinergismo dos movimentos dos membros superiores para alcançar um determinado alvo, um objetivo.

Um estudo realizado por Mc DONELL, em 1975, descrito por CLIFTON e col. (1993), mostra que a criança utiliza a visão para guiar quando é necessário um desempenho na ação, mas não exclui o uso da pista proprioceptiva para conduzir a mão quando privada de pistas visuais.

Complementando esse raciocínio, Mc CARTY e col., em 2001, explica que a criança aprende a usar a visão de uma maneira prospectiva para ter um bom desempenho em relação às demandas do ambiente. Uma preensão eficiente requer uma preparação da mão, como também ajustes após o contato com o objeto apreendido.

As avaliações mostraram que 33\% das crianças do grupo C, entre 7-9 meses, apresentaram um déficit em relação à exploração do objeto em comparação com os demais grupos. Entretanto, não foi encontrado nos artigos pesquisados nenhum estudo relacionado a esse item.

Com estes resultados, é possivel supor que um dos prováveis motivos do Grupo C ter apre- sentado um pior desempenho em relação aos demais dois grupos esteja relacionado com o ambiente muitas vezes pobre em estímulos táteis, visuais, entre outros.

Foi observado que as 68 crianças ( 100\%) avaliadas apresentaram sincinesias ao realizar o alcance e durante a manipulação dos objetos, o que mostra que a criança durante essa idade ainda não apresenta um bom sinergismo dos movimentos para realizar uma determinada tarefa.

SHEPHERD (1996) explica que esses "movimentos associados", "reações associadas" ou "movimentos em espelho" são muito evidentes, principalmente durante a manipulação, embora possam ocorrer em outros movimentos uma vez que o lactente e a criança de tenra idade podem ser incapazes de inibir músculos desnecessários para a execução de um determinado ato motor.

As 68 crianças (100\%) apresentaram preensão bimanual, uma simetria ao realizar o alcance, umas com maior e outras com menor freqüência, durante a manipulação dos objetos.

WOLFF e col. (1983, in SHEPHERD, 1996) descrevem que a tendência para a simetria é observada na criança pequena e diminui ao longo da primeira década de vida. SHEPHERD complementa ainda que há poucos estudos sobre o desenvolvimento de atividades bimanuais, pois é um desafio para a criança coordenar as duas mãos para manipular os objetos, o que implica a ação das duas mãos agindo praticamente como uma unidade, no que se refere às condições de tempo, espaço e atividade muscular.

Das crianças institucionalizadas entre 1012 meses, 60\% não apresentaram uma boa exploração em relação ao dedo indicador. No grupo A, 44\% não obteve um resultado satisfatório.

Dentre todas as crianças avaliadas, 66 delas (97\%) mostraram uma preferência em realizar a preensão com o lado direito. Duas crianças (3\%) mostraram preferência para o lado esquerdo, sendo uma criança de 5 e outra de 8 meses.

Para FLEHMING (2002), a criança começa a desenvolver uma mão dominante lentamente aos sete meses de idade. Já aos oito meses, mostra uma predileção por uma das mãos, apesar de a criança ainda trabalhar muito com as duas mãos.

\section{CONCLUSÃO}

Pode-se concluir que, dentre as crianças avaliadas, as institucionalizadas apresentaram atraso no desenvolvimento da preensão manual na maioria dos itens avaliados, principalmente em relação ao tipo de preensão a ser realizado, ao 
controle de tronco e à exploração com o dedo indicador.

Observou-se que o ambiente em que a criança vive e as experiências que ela tem são fatores importantes que podem interferir nesse desenvolvimento. Dessa forma, o fisioterapeuta, assim como outros profissionais, pode ter um papel importante no desenvolvimento infantil, principalmente por meio da prevenção, orientando, observando e avaliando as necessidades de cada criança para que problemas futuros sejam evitados ou minimizados. É necessário verificar qual é a causa do problema que impede a criança de conseguir alcançar e manusear o objeto ou que dificulta esse processo. Aprendendo como as crianças respondem e se adaptam às influências que as cercam, poderemos oferecer um ambiente favorável para que ela consiga desenvolver-se integralmente, adquirindo, assim, a sua independência.

Abstract: The objective of this study was to evaluate the development of manual prehension in infants from 4 to 12 months of age who spend most of their time in institutions (private and municipal nurseries), analyzing whether there is a delay in prehension development or not, and what are the possible factors that may be interfering in the development. Evaluation of manual prehension development was not found in the literature, as far as the items analyzed in this study are concerned. Thus, the evaluation was based on the literature considering prehension development and the age of the children. Sixty-eight boys and girls from 4 to 12 months of age were evaluated and divided into three groups: A, B, and C. The results showed that the children from institutions presented a delay in manual prehension development in most of the analyzed items. Taking into account the environment and the routine of these children, it was possible to notice that there was lack of space, toys and tactile and sensory-perceptive stimuli that could help in the acquisition of new prehension and object handling patterns. Physiotherapists, therefore, have an important role in the prevention of this problem. Their job concerns the transmission of their knowledge related to children development, particularly manual prehension, analyzing and observing the needs of each child so that they can interfere, when necessary, and minimize or avoid deficits in children's manual abilities.

Key-words: children's development; manual prehension.

\section{REFERÊNCIAS BIBLIOGRÁFICAS}

Bee H. A criança em desenvolvimento. $7^{\mathrm{a}}$ ed. Porto Alegre: Artes Médicas, 1996.

Bobath BK. Desenvolvimento motor nos diferentes tipos de paralisia cerebral. $1^{a}$ ed. São Paulo: Manole, 1989.

Brandão S. Desenvolvimento psicomotor da mão. $1^{\mathrm{a}}$ ed. Rio de Janeiro: Enelivros, 1984.

Bueno JM. Psicomotricidade teoria e prática: estimulação, educação, reeducação. $1^{\text {a }}$ ed. São Paulo: Louvise, 1998.

Burns MD. Fisioterapia e crescimento na infância. $1^{a}$ ed. São Paulo: Santos, 1999.

Case-Smith J. et al. An analysis of relationship between proximal and distal motor control. American Journal for Occupational Therapy, 1989; 43: 657-62.

Case-Smith J. et al. Perceptual-motor coupling in the development of grasp. American Journal for Occupational Therapy, 1998; 2: 102-10

Clifton RK. et al. Is visually guided reaching in early infancy a mythy? Child Development, 1993; 64: 1099-10.

Coriat LF. Maturação psicomotora no primeiro ano de vida. $3^{\wedge}$ a. ed. SãoPauio: Editora Moraes, 1991.

Ehardt RP. Níveis seqüenciais de preensão. Revista Benjamin Constant, 1997,7.

Flehming I. Texto e atlas do desenvolvimento normal e seus desvios no lactente. $l^{\wedge}$ a. ed. São Paulo: Atheneu, 2002.

Geseil A. A criança dos 0 aos 5 anos. $3^{\text {a }}$ ed. São Paulo: Martins Fontes, 1992.
Hammarstron CR, Fortes DDT, Fliedrich LR, Kliewer WA. Prevenção primária de atrasos no desenvolvimento da preensão manual em crianças de 0-3 anos. Fisioterapia em Movimento, 1992; 4: 27-45.

Holstein RR. The development of prehension in normal infants. American Journal Occupatio-nal Therapy, 1982; 36: 170-5.

Knobloch H, Passamanick B. Diagnóstico do desenvolvimento. $3^{\mathrm{a}}$ ed. São Paulo: Atheneu, 1987.

Lê B. O desenvolvimento psicomotor do nascimento ate 6 anos. $7^{\mathrm{a}}$ ed. Porto Alegre: Artes Médicas. 1992.

Mc Carty, ME, Clifton, RK, Ashmead DH, Lee P, Goube, N. How infants use vision for grasping objects Child Development, 2001; 72: 973-87.

Meyerhof PG. O desenvolvimento normal da preensão Revista Brasileira Crescimento Desenvolvimen to Humano, 1994; 4: 25-9.

Santos DCC., Gabbard C, Goncalves VVG Motor development during the first year: A comparative study. Journal Genetic Psycholo-gy, 2001; 162 143-53.

Shepherd RB. Fisioterapia em pediatria. $3^{\mathrm{a}}$ ed. São Paulo: Santos Livraria e Editora, 1996.

Siddiqui A. Object size as determinant of grasping in infancy. Journal Genetic Psychology, 1995;156. 345-55

Recebido em 01/11 /2004

Modificado em 23/01/2004

Aprovado em 17/03/2004 